\title{
Determination of Esters in Imitation Flavoring Extracts ${ }^{1,2}$
}

\author{
By George F. Beyer
}

Industrial Alcohol, and Chemical Division, Bureau of Internal Revenue, Treasury Department, Washinaton, D. C.

The following paper describes the method developed and used by the Bureau of Internal Revenue for the determination of esters in imitation flavoring extracts. All commonly used esters are completely recovered by distillation with 50 per cent alcohol, forovided the receiving flask is properly closed with a mercury trap valve: All imitation flavoring extracts should be distilled before total esters are determined, since reducing sugars which may be present will react with the alkali. Water is not a satisfactory saponification medium.

$\mathrm{T}$ HE fixing of certain standards to which imitation flavoring extracts manufactured under the provisions of the National Prohibition Act must conform has raised some questions as to the analytical methods best employed in determining the ester content of such extracts. It has therefore seemed desirable to review the methods for ester determination commonly employed, with a view to determining the best analytical method to be used. It is furthermore desirable that the manufacturing interests concerned be acquainted with the method now used in the laboratories of the Bureau of Internal Revenue in order that they may properly supervise their manufacturing operations.

\section{Preliminary Invesuigation}

Solutions were made up containing only one ester or containing mixtures of esters commonly used. With only one ester a 2 to 4 per cent solution in 50 per cent of ethyl alcohol was employed. Solutions containing from 4 to 10 per cent of mixed esters in 50 per cent of alcohol were used for the composite nixtures. The principal esters used were ethyl acetate, amyl acetate, amyl butyrate, amyl valerinate, oenanthic ether, and sebacic ether. The composite mixtures were:

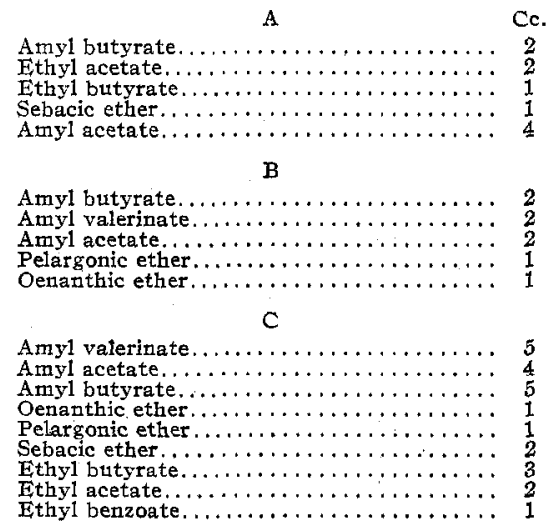

These three mixtures were made up to $250 \mathrm{cc}$. at $60^{\circ} \mathrm{F}$. in sufficient alcohol and water to effect solution.

SAPONIFICATION MEDIA-The first point to be considered was the best medium for completeness of saponification. This was tested by the A. O. A. C. method, without distillation. When water was used as the saponification medium with 10-cc. portions of the single and composite ester mix-

I Received November 10, 1921.

Published by permission of the Commissioner of Internal Revenue. tures, the results were low. The addition of 25 cc. of 95 per cent ethyl alcohol as a saponification medium gave results practically in accordance with the calculated content of esters present.

TIME REQUIRED-Solutions of ethyl acetate showed 96 per cent saponification after 5 mins.' refluxing on the steam bath and complete saponification after 10 mins.' refiuxing. The same solution was allowed to stand with alkali in a tightly stoppered flask, at room temperature, and shaken well every $5 \mathrm{~min}$. for $0.5 \mathrm{hr}$. Another solution was alloned to stand at room temperature in a tightly stoppered flask in the presence of alkali over night. Saponification was complete in both cases.

A similar series of experiments with amyl acetate disclosed the fact that 94 per cent of the ester was saponified by refluxing for $5 \mathrm{~min}$. over the steam bath, and saponification was complete in $10 \mathrm{~min}$. The similarity of the results obtained with amyl acetate seem to offer additional proof of the theory of ester transposition, that is, that amyl acetate in the presence of a large excess of ethyl alcohol and alkali is transposed into ethyl acetate and amyl alcohol before saponification begins, it being a well-known fast that the speed of the reaction of the transposition is many times more rapid than the saponification of the ester.

Ten-cc. portions of ethyl acetate, amyl acetate, and amyl butyrate mixtures were allowed to stand over night with an excess of standard alkali, and were finally refluxed for $0.5 \mathrm{hr}$. on the steam bath. Other 10-cc. portions of the same mixtures were immediately refluxed on the steam bath for 0.5 and $1 \mathrm{hr}$., respectively. Saponification was complete in each instance.

Ten cc. of an imitation peach extract of known composition were treated in a similar manner. It was found that in all cases more complete saponification was obtained when the solution was allowed to stand over night before refluxing for $0.5 \mathrm{hr}$. on the steam bath. The low results obtained from immediate refluxing were attributed to the probable escape of some of the esters through the air condenser. It was also possible that the saponification of the imitation peach extract was incomplete, but the fact was not definitely determined.

Pardee and Reid ${ }^{3}$ have shown that it is impossible to obtain results which are concordant or even close to 100 per cent of the ester present when certain esters are saponified in methanol by refluxing for $1 \mathrm{hr}$. on the steam bath with the ordinary 3 -ft. air condenser. They attribute this to the escape of the ester through the condenser.

One experiment was undertaken to see if this possible losis through the air condenser could be prevented. Two 5-cc. portions of a 4 per cent solution of amyl acetate in methyl alcohol were saponified in methanol as the saponification medium. One portion was refluxed immediately for $0.5 \mathrm{hr}$. on the steam bath; the other was allowed to stand in a tightly stoppered flask at room temperature for $1 \mathrm{hr}$., with thorough shaking every $5 \mathrm{~min}$., and then refluxed for $0.5 \mathrm{hr}$. on the steam bath. Approximately 98 per cent of the calculated amount was found when the solution was refluxed immediately, while practically 100 per cent were found in the other case.

\footnotetext{
Thrs Journai, 12 (1920), 129.
} 